\title{
No impact of a short-term climatic "El Niño" fluctuation on gut microbial diversity in populations of the Galápagos marine iguana (Amblyrhynchus cristatus)
}

\author{
Alejandro Ibáñez ${ }^{1,2}$ (D) Molly C. Bletz ${ }^{1,3} \cdot$ Galo Quezada $^{4} \cdot$ Robert Geffers $^{5} \cdot$ Michael Jarek $^{5} \cdot$ Miguel Vences $^{1} \cdot$ \\ Sebastian Steinfartz ${ }^{1,6}$
}

Received: 26 May 2020 / Revised: 26 November 2020 / Accepted: 29 November 2020 / Published online: 2 February 2021

(C) The Author(s) 2021

\begin{abstract}
Gut microorganisms are crucial for many biological functions playing a pivotal role in the host's well-being. We studied gut bacterial community structure of marine iguana populations across the Galápagos archipelago. Marine iguanas depend heavily on their specialized gut microbiome for the digestion of dietary algae, a resource whose growth was strongly reduced by severe "El Niño"-related climatic fluctuations in 2015/2016. As a consequence, marine iguana populations showed signs of starvation as expressed by a poor body condition. Body condition indices (BCI) varied between island populations indicating that food resources (i.e., algae) are affected differently across the archipelago during 'El Niño' events. Though this event impacted food availability for marine iguanas, we found that reductions in body condition due to "El Niño"-related starvation did not result in differences in bacterial gut community structure. Species richness of gut microorganisms was instead correlated with levels of neutral genetic diversity in the distinct host populations. Our data suggest that marine iguana populations with a higher level of gene diversity and allelic richness may harbor a more diverse gut microbiome than those populations with lower genetic diversity. Since low values of these diversity parameters usually correlate with small census and effective population sizes, we use our results to propose a novel hypothesis according to which small and genetically less diverse host populations might be characterized by less diverse microbiomes. Whether such genetically depauperate populations may experience additional threats from reduced dietary flexibility due to a limited intestinal microbiome is currently unclear and calls for further investigation.
\end{abstract}

Keywords Gut microbial diversity $\cdot$ El Niño $\cdot$ Starvation $\cdot$ Body condition $\cdot$ Host genetic diversity $\cdot$ Marine iguana populations

\section{Introduction}

A wide variety of microbial communities exist in the gastrointestinal tract of vertebrates, constituting the gut microbiome

Alejandro Ibáñez, Molly C. Bletz shared first authorship

Communicated by: Matthias Waltert \& Paula Roig Boixeda

Alejandro Ibáñez alejandro.ibanez@uj.edu.pl

Sebastian Steinfartz steinfartz@uni-leipzig.de

1 Zoological Institute, Technische Universität Braunschweig, Braunschweig, Germany

2 Present address: Department of Comparative Anatomy, Institute of Zoology and Biomedical Research, Jagiellonian University, ul. Gronostajowa 9, 30-387 Kraków, Poland
(Ley et al. 2008; Parfrey et al. 2014). Gut microorganisms are essential for their vertebrate hosts, as demonstrated by their involvement in many vital processes such as food digestion and proper nutrient extraction (Ley et al. 2006; Rubino et al.
3 Department of Biology, University of Massachusetts Boston, Boston, MA, USA

4 Dirección Parque Nacional Galápagos, Puerto Ayora, Santa Cruz, Galápagos, Ecuador

5 Department of Genome Analytics, Helmholtz Centre for Infection Research, 38124 Braunschweig, Germany

6 Institute of Biology, Molecular Evolution and Systematics of Animals, University of Leipzig, Talstrasse 33, 04103 Leipzig, Germany 
2017); regulation of immune response (Maslowski et al. 2009); defense against pathogenic agents (Kamada et al. 2013); and adequate intestinal homeostasis (Sommer and Bäckhed 2013). Despite the importance of the gut microbiome to a host's well-being, the mechanisms modulating the structure and diversity of gut microbial communities remain poorly known, especially for non-model vertebrate organisms.

External environmental factors strongly influence the gut microbiome of a host organism, and, across many species, diet is one of the most important factors affecting the composition and structure of a host's microbiome (Turnbaugh et al. 2008; Pop 2012; Bolnick et al. 2014a). Host exposure to distinct bacterial reservoirs (e.g., where microorganisms are acquired from the host's environments) can, in association with the different food items consumed, lead to diet-related shifts in the host's bacterial community (Nelson et al. 2013; Smith et al. 2015; Bletz et al. 2016). Starvation experienced by a host may have different effects on microbial composition and structure, depending on the specific species of the vertebrate host (Kohl et al. 2014). Besides diet, the composition of enteric bacterial communities depends on multiple other host-specific factors that influence the overall composition of the gut microbiome. These include acidity in the gastrointestinal tract (Beasley et al. 2015); antimicrobial peptides (Ostaff et al. 2013); as well as neutral and adaptive genetic characteristics of the host (Benson et al. 2010; Spor et al. 2011; Bolnick et al. 2014b) but also age, physiological state, and health status (Greenhalgh et al. 2016).

The marine iguana (Amblyrhynchus cristatus) represents a suitable natural system to study the influence of diet and starvation on the gut microbiome. Marine iguanas forage in the tidal and intertidal zones where they consume macrophytic algae (Wikelski et al. 1993) - with a preference for different species of green (Ulva sp.) and red algae (Centroceras sp. and Gelidium sp.) (Shepherd and Hawkes 2005; Vitousek et al. 2007). This diet has promoted the establishment of a specialized bacterial community, which is involved in the fermentation and digestion of these algae in their hindguts (Mackie et al. 2004; Hong et al. 2011). In fact, microbiome composition revealed from fecal samples clearly distinguishes A. cristatus from herbivorous reptiles that consume terrestrial plants - including its sister taxon, the Galápagos land iguana (Conolophus subcristatus) (Lankau et al. 2012).

Climatic phenomena are among the principal forces regulating animal population dynamics. The "El Niño"-Southern Oscillation [ENSO] affects climate conditions worldwide, and the so-called "El Niño" events are one part of the ENSO. Climatic conditions of the Galápagos archipelago are strongly influenced by ENSO activity, and the increase in sea-surface temperatures during severe "El Niño" events can have devastating effects on the marine ecosystem (Barber and Chavez 1983). Typically, during "El Niño" periods, green and red algal species are replaced by brown algae that are difficult to digest, reducing the amount of edible algae and leading to widespread starvation and mortality among marine iguanas (Laurie 1990; Laurie and Brown 1990; Wikelski and Nelson 2004). Accordingly, the dynamics of marine iguana island populations are strongly driven by starvation in the course of severe "El Niño" events. "El Niño" events can have a negative short-term effect on the nutritional status (i.e., body condition) of marine iguana individuals, which may feedback into the respective population dynamics. However, after these events - when edible algae regrowmarine iguana populations can recover quickly (Wikelski and Nelson 2004). For instance, Romero and Wikelski (2001) found that the body condition in five out of six island populations of marine iguanas was significantly lower at the end of the severe "El Niño" famine event of 1998 compared to "normal" conditions 1 year later during the feast La Niña period. Despite all the above, the extent to which the gut microbiome of marine iguanas is influenced by periods of starvation in the course of recurrent "El Niño" events is still unknown.

Despite recognition of the role that the hosts' genotype plays in influencing its microbiome, we lack knowledge regarding how environmental conditions and evolutionarily relevant parameters of host populations - as represented by its distinct host individuals - impact the composition of the gut microbiome in a specific host population. One such key evolutionary parameter is the genetic diversity of a population. Genetic diversity is strongly connected to the ability of a population to adapt to changing environmental conditions and therefore influences its viability over time (Frankham 2005).

Marine iguanas provide a natural system to study the effects of climatic disturbance through recurring "El Niño" events on the composition and structure of the specialized gut microbiome in the context of short-term starvation events. They are structured into several genetically distinct island populations (subspecies) - displaying markedly different genetic population parameters (Steinfartz et al. 2009; MacLeod et al. 2015a; MacLeod and Steinfartz 2016; Miralles et al. 2017) - offering the possibility to explore the correlation of such parameters on microbiome diversity and composition. In this study, we sampled marine iguanas across the archipelagos' major island populations during the course of the most recent severe "El Niño" event in 2015/2016. By comparing individual body condition of sampled individuals with their gut bacterial diversity, we aimed to estimate the impact of starvation events on the bacterial diversity of marine iguanas. Besides, we developed a novel, testable hypothesis of how host genetic diversity may influence microbiome diversity.

\section{Materials and methods}

\section{Study design and sampling}

Individual marine iguanas were sampled between December 2015 and January 2016, coinciding with the most severe "El 
Niño" event since the last severe event in 1997/1998. Marine iguanas were captured with a lasso, if possible sexed, and their body mass and total length were measured to determine their body condition (see below). A sample representative of the gut microbiome was also taken by gently introducing a sterile swab into the cloaca and the gastrointestinal tract. This is a valid method to sample gut microbial communities in reptiles (Martin et al. 2010; Colston et al. 2015; Price et al. 2017) rather than fecal samples. To avoid resampling the same individual, sampled individuals were marked with a small spot of paint. Individual swabs were stored in plastic tubes in absolute ethanol and kept cold until laboratory analysis. Overall, 379 iguanas from 13 distinct locations on 11 islands were sampled for their gut microbiome, representing all major island populations and most of the current subspecies of Amblyrhynchus cristatus (MacLeod et al. 2015a; Miralles et al. 2017). Due to logistical reasons, the most northern islands of the archipelago - Wolf and Darwin - were not sampled. In order to obtain an insight into gut microbiome diversity and community structure on the level of its host populations, we sampled approximately 20-30 marine iguana individuals at each of the 13 sites (see Fig. 1 and Table 1 for the exact numbers per location). The sealed tubes containing cloacal swab samples belonging to the same site were kept together in separate plastic bags to avoid cross contamination among sites. A control sample was taken with a clean swab waved for a short time in the air to be exposed to potential bacteria present in the environment. Otherwise, this swab was handled the same way as the sampling swabs.

\section{Gut microbial DNA extraction and amplicon sequencing}

Cloacal and control swabs were extracted with the MoBio Power Soil Extraction Kit as previously described (SabinoPinto et al. 2016) for each independent sample. The V4 region of the 16S rRNA gene was PCR-amplified with dual index primers as previously described (Kozich et al. 2013). PCR amplicons were pooled in approximately equimolar concentrations, and the final DNA concentration was determined with a Broad-Range dsDNA kit (Promega) on a qubit. Pooled amplicons associated with each sample were sequenced using paired-end $2 \times 250$ v2 Illumina sequencing technology on an Illumina Miseq, at the Genome Analytics department of the Helmholtz Center of Infection Research in Braunschweig (Germany).

Raw sequence data were demultiplexed and quality-filtered using the software Quantitative Insights Into Microbial Ecology (QIIME) (Caporaso et al. 2010), under the following parameters: no Ns within the nucleotide sequence, no barcode errors, and a minimum of three consecutive low-quality base calls (minimum $\mathrm{q}=10$ ) before read truncation. Only forwardreads were used, because reverse reads typically suffer from lower quality and were a priori excluded (Kwon et al. 2013). Quality-filtered sequences were clustered into sub-operational taxonomic units (sOTUs) using the deblur workflow (Amir et al. 2017) [https://github.com/biocore/deblur]. Within this workflow, all sequences were trimmed to $150 \mathrm{bp}$, and sOTU clusters with less than 10 reads across all samples were removed. Chimeras were processed and filtered following the deblur workflow (Amir et al. 2017). Taxonomy was assigned with the Ribosomal Database Project Classifier (Wang et al. 2007) using a custom bash script, and a phylogenetic tree was built in QIIME using FastTree (Price et al. 2010). After quality and low-abundance sOTU filtering, $6,379,181$ sequences were retained (mean 17,382 $\pm 15,678$ SD reads per sample). Samples were subsequently rarefied at 2500 reads per sample to normalize read counts across samples (Fig. S1). This depth was chosen because it (1) adequately captured the majority of the bacterial richness present in the samples and (2) allowed the inclusion of the majority of the samples. In total, 332 samples out of 379 were retained after quality filtering and rarefying the data.

\section{Estimation of body condition index of individual marine iguanas}

Marine iguanas were measured for total length (TL) and weighed after being captured; TL was measured as the distance from the tip of the snout to the tip of the tail using a metric tape. Body mass was determined on a scale $( \pm 5 \mathrm{~g})$. The residuals of a linear regression between the values of both body mass and TL (both transformed to the natural logarithm) were used as the body condition index (BCI). This and similar analyses were carried out with the GLM procedure in Statistica software (StatSoft Inc., USA). This approach results in similar estimates of BCI based on the formula (body mass/ snout-vent length $\left.{ }^{3}\right) \times 10^{6}$ ) (Laurie 1990; Wikelski and Trillmich 1997). It offers the advantage of a more straightforward and unbiased categorization but is also more conservative. Negative values (i.e., residuals) are representative of a poorer than expected body condition, and we rated those individuals as being starved. Positive values indicate a good body condition, and we assumed that such individuals did not suffer from starvation. Data of the gut microbiome were available for 332 samples, but due to missing data, six samples were excluded for BCI calculation leaving a total sample size of 326 in this analysis (see Table 1 for the number of samples per island in the analyses). We first explored whether BCI differed among sex categories and populations by performing a GLM followed by a post hoc Tukey test if a significant effect in a given factor was found. Moreover, BCI was also used to analyze the relationship between starvation and gut microbial alpha diversity, hereafter termed species richness. As marine iguanas show strong sexual size dimorphism (Chiari et al. 2016), we also calculated the BCI for each sex category 
Fig. 1 Gut bacterial community composition and body condition index (residuals from a log regression of weight and size) of marine iguanas across distinct island populations of the Galápagos archipelago in the "El Niño" year 2015/2016. (A) Sampled populations with bar plots showing the percentage of bacterial operational taxonomic units (OTUs) (most common taxa) per phylum for each host population. (B) Boxplot showing body condition index $(\mathrm{BCI})$ of marine iguana populations studied (median, 25-75\% percentiles, non-outlier range, outliers, and extremes; as calculated in

Statistica software (StatSoft Inc)). Negative BCI values indicate starvation of individuals. San Cristóbal-Isla Lobos is not shown. Sample sizes are shown in Table 1. See also Fig. S2 for a ranked illustration of BCI values

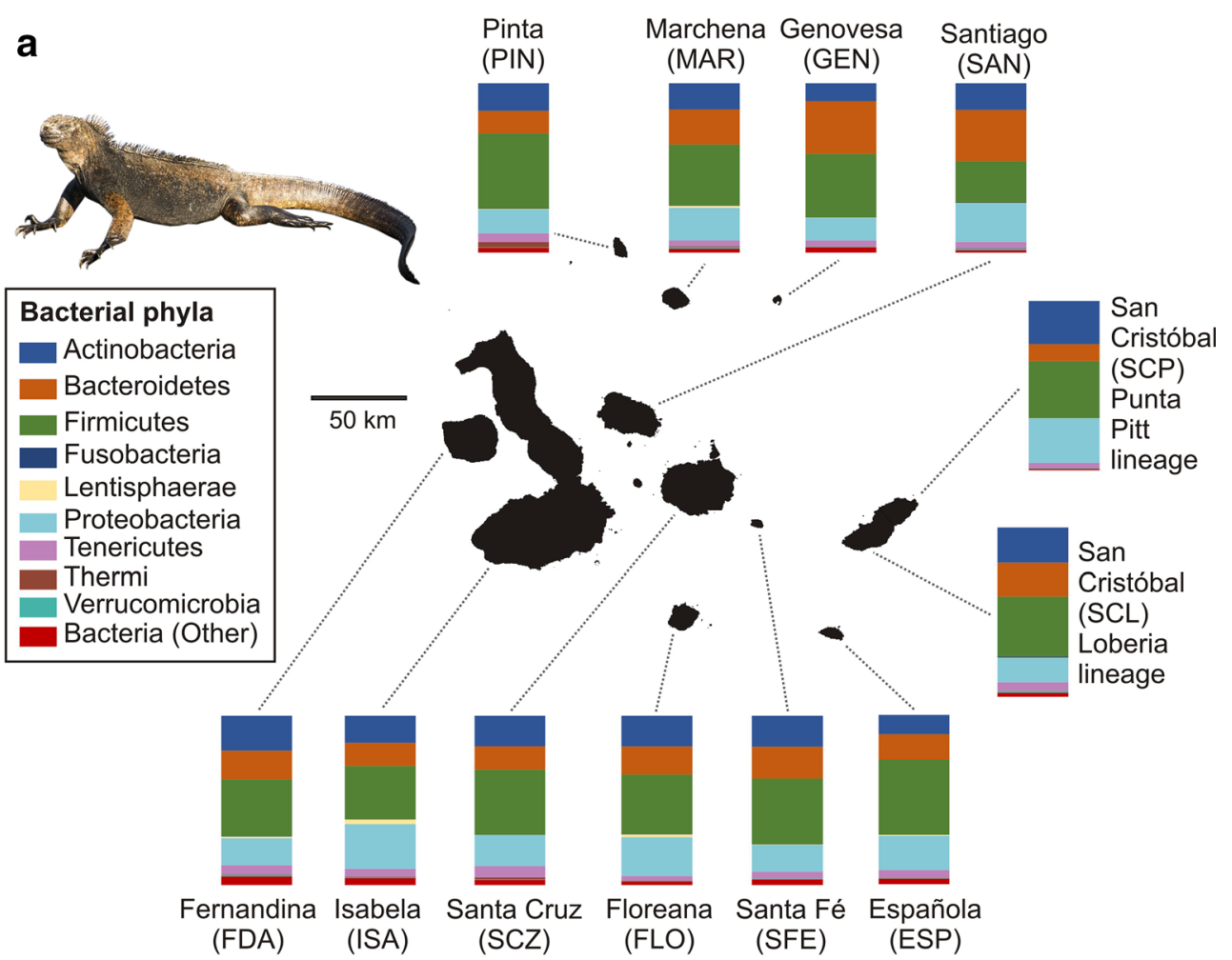

b

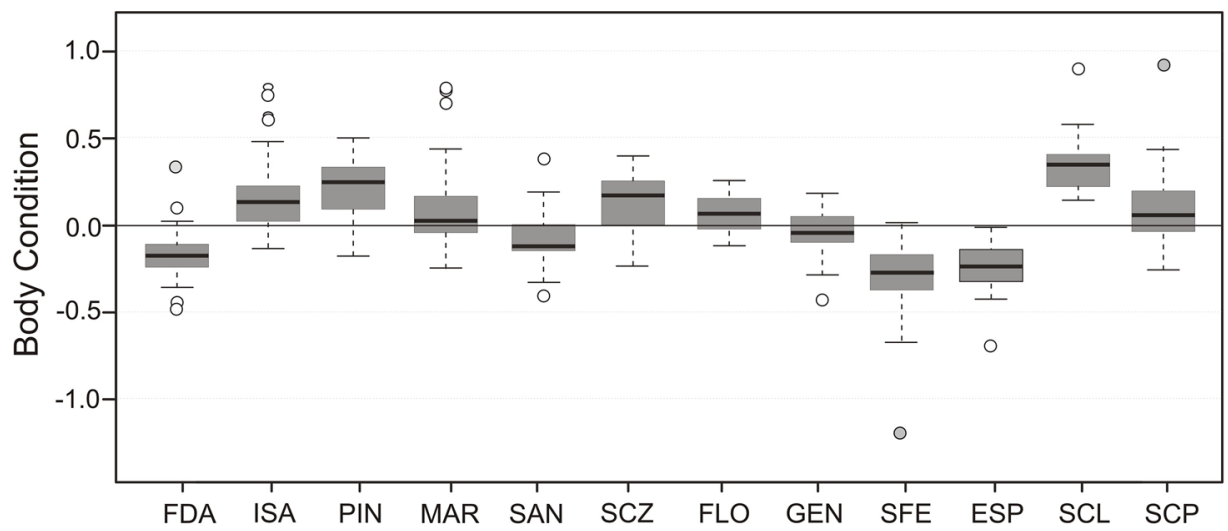

separately and correlated these values to microbial species richness, as an additional analysis (see Table S1 in Online Resource 1). In order to demonstrate the negative effects on BCI (i.e., starvation), we calculated BCI values for sampled marine iguanas at the same localities in June/July of 2004, which is documented as a non-"El Niño" year (United States Climate Prediction Center 2019) associated with presumably normal foraging conditions for marine iguanas. We only compared individuals from the same sites on an island. Accordingly, BCI was calculated for 612 marine iguanas from nine sites (i.e., sample size for year 2004, 392; sample size for year 2015/2016, 220). BCI values were compared for matching pairs of islands between the years and as the median across populations of each sampling period. Furthermore, differences between year and matching pair of sites were tested by performing a GLM with BCI values as dependent variable and site and year and the interaction between both site and year as factors. Tukey post hoc tests were carried out to explore formal differences between matching pairs of sites from both years.

\section{Analysis of genetic diversity parameters of marine iguana host populations}

Genetic diversity of marine iguana host populations was estimated from a previous comprehensive dataset based on 12 polymorphic nuclear microsatellite loci downloaded from the Dryad data repository [https://doi.org/10.5061/dryad. 
Table 1 Population (island location) name, population abbreviation (Abbr.), and number of samples collected in 2015/2016

\begin{tabular}{|c|c|c|c|c|c|c|c|c|c|}
\hline Island & $A b b r$. & $N$ (Samples) & $N$ (Micro) & $N(B C I)$ & $M$ & $F$ & $J / U$ & $N / A(B C I)$ & N/A (Sex) \\
\hline Española & ESP & 30 & 26 & 24 & 13 & 11 & 0 & 2 & 2 \\
\hline Fernandina & FDA & 30 & 27 & 27 & 13 & 14 & 0 & & \\
\hline Floreana & FLO & 30 & 22 & 21 & 12 & 8 & 1 & 1 & 1 \\
\hline Genovesa & GEN & 21 & 20 & 20 & 7 & 13 & 0 & & \\
\hline Isabela & ISA & 29 & 26 & 24 & 19 & 5 & 2 & 2 & \\
\hline Marchena & MAR & 30 & 29 & 29 & 17 & 5 & 7 & & \\
\hline Pinta & PIN & 30 & 29 & 29 & 7 & 21 & 1 & & \\
\hline Santiago & SAN & 30 & 21 & 20 & 13 & 7 & 0 & 1 & 1 \\
\hline San Cristóbal-Isla Lobos & $\mathrm{SCI}$ & 30 & 26 & 26 & 7 & 5 & 14 & & \\
\hline San Cristóbal-Loberia & SCL & 30 & 26 & 26 & 18 & 8 & 0 & & \\
\hline San Cristóbal-Punta Pitt & $\mathrm{SCP}$ & 30 & 28 & 28 & 19 & 7 & 2 & & \\
\hline Santa Cruz & $\mathrm{SCZ}$ & 29 & 23 & 23 & 9 & 14 & 0 & & \\
\hline Santa Fe & SFE & 30 & 29 & 29 & 15 & 12 & 2 & & \\
\hline
\end{tabular}

$N$ (samples) = number of samples collected in the field (total number is 379$)$. $N$ (micro) = number of samples for which microbial diversity could be determined (total number is 332 ). $N(\mathrm{BCI})=$ number of samples considered for the calculation of body condition index (BCI; total number is 326$)$. Sex is classified by three categories: $M$ males, $F$ females, and $J / U$ undetermined sex or juveniles/subadults. $N / A$ (BCI) body condition data is not available. $N / A$ (Sex) sex is not available. Metadata on island origin is considered for the samples included in statistical analysis of microbial diversity, $N($ micro $)=332$. Metadata on sex and body condition has slightly different final sample sizes due to missing data

pp6bm] (MacLeod et al. 2015b). This dataset includes 614 individual marine iguana genotypes that have been extracted by random pruning from a large dataset of 1500 genotyped samples from different time points [1991/1993; 2004; and 2011-2014] to avoid overrepresentation of certain island populations (MacLeod et al. 2015a). In general, for each island population or subspecies of $A$. cristatus, up to 50 individuals were randomly pruned from the large dataset, while sampling sites with less than 20 genotyped individuals were discarded (MacLeod et al. 2015a). Since there was no observable shortterm impact of the 1997 "El Niño" event on the genetic population structure of marine iguana populations (Steinfartz et al. 2007), this dataset of 614 individuals should be representative of the overall population genetic structure and corresponding parameters despite being sampled at various time points. Population genetic analyses of the microsatellite dataset were performed with the R software (R Core Team 2013) using the interface Rstudio unless otherwise stated. Genetic distance matrices were calculated using the dist.genpop function (package adegenet (Jombart 2008)), based on Nei's distance and angular distance or Edwards' distance. Additionally, we estimated several important genetic diversity parameters for each population, including gene diversity (i.e., mean expected heterozygosity, $\left.H_{S}\right)$, mean observed heterozygosity $\left(H_{\mathrm{o}}\right)$, and rarefied mean allelic richness (AR), in the software packages GenAlEx 6.5 (Peakall and Smouse 2006, 2012) and the $\mathrm{R}$ packages adegenet (Jombart 2008) and PopGenReport (Adamack and Gruber 2014). The function allel.rich (package PopGenReport) was used to calculate a rarefied mean allelic richness.

\section{Analysis of bacterial diversity and community structure}

Bacterial beta diversity was calculated as Bray-Curtis dissimilarity among individuals from all populations. To test for differentiation of bacterial communities among populations, a permutational multivariate analysis of variance (PERMANOVA) was performed, followed by a pairwise comparison with the software PRIMER 7 and R package RVAideMemoire (Hervé 2017). Heterogeneity of multivariate dispersions was evaluated using the betadispers function from the vegan package (Oksanen et al. 2019). In order to explore the contribution of geographical and genetic distances to among-island variation on beta diversity of gut microorganisms, we ran multiple regression on distance matrices (MRM) with the R package ecodist (Goslee and Urban 2007); for these analyses, we used Nei's genetic distance (see Table S2 in Online Resource 1). Additionally, this analysis was repeated using Edwards's genetic distance (seeTable S3 in Online Resource 1), leading to similar outcomes as shown in the SI. We used the function earth.dist (package fossil, Vavrek 2011) to generate a geographical distance matrix by calculating pairwise distances between sampling locations based on geographic coordinates (both geographic coordinates and geographic distance matrix are shown in Online Resource 1; see Tables S4 and S5, respectively). Genetic distance matrices were computed as described above. Bacterial distances between populations were calculated by averaging the pairwise distances between all individuals from the respective populations. As genetic and geographic distances were positively 
correlated (Mantel test $r=0.426 ; P=0.001$ ), we performed partial Mantel tests with the package vegan (Oksanen et al. 2019) to further explore the partial effect of each of these variables when controlling for the effects of both genetic and geographic distances on beta diversity of gut microbiome. Note that for this last analysis, only Nei's genetic distance matrix was used.

Bacterial diversity was calculated to explore the impact of starvation as well as genetic population parameters on gut bacterial diversity. We used the calculated species richness (total number of sOTUs) as obtained from QIIME. Differences in species richness among populations and sex categories were explored by carrying out a GLM followed by post hoc Tukey tests if a factor showed a significant $P$ value $(P<0.05)$. This analysis included 328 individuals - as sex was not available for four of the samples (see Table 1 for details on sample sizes). Simple linear regressions were used to investigate whether species richness was related to host genetic diversity for each population and body condition. Linear regression models to illuminate the relationship between bacterial diversity and genetic parameters were performed at the population level. Accordingly, the average of the species richness was calculated for each population, and these values were used in the regression. Moreover, as some of the variables did not achieve normality and/or due to the small sample size in some analyses, we performed Spearman correlations besides the linear regressions to confirm our results. A Spearman correlation was performed on the averaged BCI per each population versus gene diversity $\left(H_{S}\right)$, showing that genetic diversity and starvation are independent parameters $\left(r_{\mathrm{s}}=-0.077 ; p=0.812\right)$.

Due to the evolutionary relationships among studied species, uncorrected correlation analyses of species traits would violate the assumption of independence among data points, making phylogenetic correction (Felsenstein 1985) necessary (reviewed by Cornwell and Nakagawa 2017). Although traits have sometimes been found to have a high phylogenetic signal also within species (e.g., Ashton 2004), Stone et al. (2011) suggest that application of phylogenetic independent contrasts is only appropriate where the relationship between populations is both tree-like and can be inferred with reasonable accuracy. Gene flow between marine iguana subspecies exists but is highly restricted, their relationships were reliably reconstructed by restriction site-associated DNA sequencing (RADseq) data (Miralles et al. 2017), and almost each of the populations studied herein belongs to a different subspecies. To exclude that the encountered trait similarities between these populations might have been caused by common evolutionary origin, we followed a conservative approach and repeated correlation analyses on microbial species richness and host genetic diversity with phylogenetic independent contrasts calculated in $\mathrm{R}$ with the ape package (Paradis et al. 2004).

In order to take the distribution (evenness) of observed bacterial OTUs into account, we calculated Shannon's effective number of species and performed similar regression analyses as for observed species richness (Jost 2006). To explore whether $\mathrm{BCI}$ is connected to functional bacterial diversity or specific taxonomic groups of bacteria, an additional analysis was carried out. We used Phylogenetic Investigation of Communities by Reconstruction of Unobserved States (PICRUSt) (Langille et al. 2013) to calculate functional richness and diversity in gut bacteria that were correlated with BCI. PICRUSt2 functional predictions for marine iguanas had a low NSTI value, which measures how well OTUs are characterized by this tool. The average NSTI value was 0.16 (sd, 0.075), which is in line with other datasets such as the Human Microbiome Project (0.11 (sd, 0.49)) (Douglas et al. 2019). In addition, correlations were performed between bacterial phyla known to be involved in fermentation (e.g., Firmicutes and Bacteroidetes) and BCI.

Unless stated otherwise, all statistical analyses were performed in Statistica v. 7 (StatSoft) and R.

\section{Results}

\section{Body condition of marine iguana island populations during the "El Niño" event 2015/2016}

Body condition differed statistically among marine iguana sex categories and populations during the "El Niño" event 2015/ 2016 (GLM: overall $\mathrm{F}_{14,311}=28.264, P<0.001$, adjusted $\mathrm{R}$ squared $=0.54$; factor sites, $\mathrm{F}_{12,311}=32.22, P<0.001$; factor sex, $\left.F_{2,311}=9.516, P<0.001\right)$. Concerning sex categories, post hoc comparisons revealed that females had statistically higher BCI than males (Tukey test: $P=0.009$ ), but all the other comparisons (i.e., subadult vs. male; subadult vs. female) remained non-significant $(P>0.32)$. As demonstrated by the distinct values of body condition index (Fig. 1B), marine iguana populations were differentially affected by the "El Niño" event. Iguanas from La Loberia on San Cristóbal (A. c. mertensi) had the highest body condition value (median, 0.337), while Santa Fe iguanas (A. c. trillmichi) were the ones most affected by starvation (median, -0.275 ) (see Fig. S2, in Online Resource 1, for a sorted comparison). In general terms, iguanas from Marchena, Santa Cruz, Floreana, Isabela, Pinta, Punta Pitt (San Cristóbal) and the abovementioned La Loberia were less affected, showing positive median values of BCI, while iguanas from Española, Fernandina, Genovesa, Santiago, Santa Fe, and Isla Lobos (San Cristóbal) had a poor condition, as indicated by negative median BCI values (Fig. 1B). Statistical significance for the multiple post hoc comparisons among marine iguana populations can be found in Table S6 (Online Resource 1).

Overall, we can find a starvation effect of marine iguana island populations, if $\mathrm{BCI}$ values found at the same sampling sites are compared between "El Niño" and non-"El Niño" 
years. BCI differed significantly among populations and years, but the interaction between both factors was also significant (overall $\mathrm{F}_{17,594}=59.06, P<0.001$, adjusted-Rsquared $=0.618$; see Table 2 and Fig. 2$)$. The overall median BCI across populations was negative in 2015/2016 (-0.129) and slightly positive (0.076) in 2004 (Fig. S3, Table S7 in Online Resource 1). Except for Pinta island, marine iguanas during the non-"El Niño" year 2004 displayed similar or substantially higher BCI values than for the same sites in 2015/ 2016 (Fig. 2). However, post hoc comparisons showed that only three (Floreana, Fernandina, and Santiago) out of nine islands/sites differed statistically between years (see Table S8 in Online Resource 1; Fig. 2).

\section{Correlates of marine iguana bacterial gut community composition and structure}

16S metabarcoding of the $\mathrm{V} 4$ region from 332 marine iguana samples revealed a total of 2711 OTUs after filtering and rarefying. Marine iguana gut bacterial communities were dominated by members of the phyla Firmicutes (36\%), Proteobacteria (19\%), Bacteriodetes (18\%), and Actinobacteria (18\%). Other phyla were also present in marine iguanas, such as Tenericutes (4\%) as well as Lentisphaerae $(0.7 \%)$ and Verrucomicrobia $(0.6 \%)$ together with other taxa found in minor amounts (see Fig. 1A for a graphical overview across the archipelago and Tables S9 and S10 in Online Resource 1 for relative abundances of phyla and orders recorded). Many bacterial genera were shared across the populations of marine iguanas. Bacteroides and Corynebacterium were common across individuals from all populations. However, this was not the case for other bacteria genera. Helicobacter, for example, showed low relative abundance to absence in the populations of Genovesa and Marchena but was common across individuals from Fernandina, Floreana, Isabela, and Punta Pitt (San Cristóbal). On the other hand, Sphingobacterium appeared to be common only in

Table 2 Output of the general linear model (GLM) exploring differences on BCI from different populations (sites) from two different temporal points, i.e., "El Niño" (2015/2016) and non-"El Niño" (2004) years

\begin{tabular}{llllll}
\hline Effect & SS & Degr. of freedom & MS & F & P \\
\hline Intercept & 0.165 & 1 & 0.165 & 5.460 & $\mathbf{0 . 0 2 0}$ \\
Site & 15.297 & 8 & 1.912 & 63.229 & $\mathbf{0 . 0 0 0}$ \\
Year & 4.706 & 1 & 4.706 & 155.623 & $\mathbf{0 . 0 0 0}$ \\
Site*Year & 5.075 & 8 & 0.634 & 20.977 & $\mathbf{0 . 0 0 0}$ \\
Error & 17.964 & 594 & 0.030 & & \\
\hline
\end{tabular}

Post hoc Tukey comparisons for the interaction Site*Year are shown in supplementary information (Online Resource 1). Significant values are marked in bold iguanas from Genovesa and Marchena. A detailed overview is provided in Fig. 3 as a heatmap.

Bacterial communities differed statistically among particular island populations (PERMANOVA: Pseudo- $F_{12,319}=$ 4.34; $p=0.001$; see Online Resource 1: Fig. S4; see Table S11 for a detailed pairwise comparison among populations). Significant differences in multivariate dispersion among populations were also detected (PERMDISP: $F$-value $12,319=6.537 ; p<0.001)$, showing that both variance and location effects may be responsible for the observed differences in bacterial community structure. A MRM revealed that interpopulation differences in bacterial beta diversity were more correlated with Nei's genetic distance (regression coefficient $=0.09 ; p=0.006$ ) than with geographical distance (regression coefficient $=-0.00008 ; p=0.346$ ); however, the overall variation explained by this model was low (MRM: $F=27.35 ; R$-squared $=0.025 ; P=0.008)$. Partial Mantel tests supported the results obtained in the MRM. A relatively strong relationship between beta diversity and genetic distance was observed when controlling for geographic distance (partial Mantel test: $r=0.383 ; p=0.026$ ). However, beta diversity did not correlate significantly with geographical distance when controlling for the effects of genetic distance (partial Mantel test: $r=0.058 ; p=0.333$ ).

Species richness differed among populations but not among sex categories (GLM: overall model $\mathrm{F}_{14,313}$ : 4.329, $P<0.001$, adjusted R-squared, 0.125 ; factor sites, $F_{12,313}=5.021$, $P<0.001$; factor sex, $F_{2,313}=0.175 ; P=0.839$ ). It was lowest in the Punta Pitt population (A. c. godzilla; 112.75 OTUs) and on Santa $\mathrm{Fe}$ (A. c. trillmichi; 130.31 OTUs), and highest on Fernandina (192.93 OTUs) and Isabela (184.42 OTUs) - both populations belong to the subspecies A. c. cristatus. A detailed overview of species richness found for the distinct island populations (subspecies) is shown in Table 3. Post hoc Tukey test comparisons among sites are shown in Table S12 (Online Resource 1). Further analysis revealed that bacterial species richness was not significantly related to body condition (simple linear regression: $F_{1,324}=0.24 ; p=0.624$; see Table 4 for detailed results and Table S1 in Online Resource 1 for the outcome considering each sex separately).

The body condition index was not related to both microbial functional richness $(R=0.008 ; p=0.88)$ and diversity $(R=-$ $0.018 ; p=0.75$ ) as estimated in PICRUSt. Explorative analysis on specific taxonomic phyla involved on fermentation and digestion did not show a clear association with marine iguana body condition. The abundance of Firmicutes showed a weak, but significant relationship with $\mathrm{BCI}(R=0.13 ; p=0.017$; Fig. S5A in Online Resource 1) while the level of Bacteroidetes was independent on BCI $(R=-0.083 ; p=0.13$; Fig. S5B in Online Resource 1).

Among all island populations, we found the highest level of genetic diversity on Fernandina $\left(H_{s}, 0.84 ; H_{\mathrm{o}}, 0.83\right.$; AR, 10.1), while marine iguanas from Pinta $\left(H_{s}, 0.63 ; H_{o}, 0.65\right.$; 


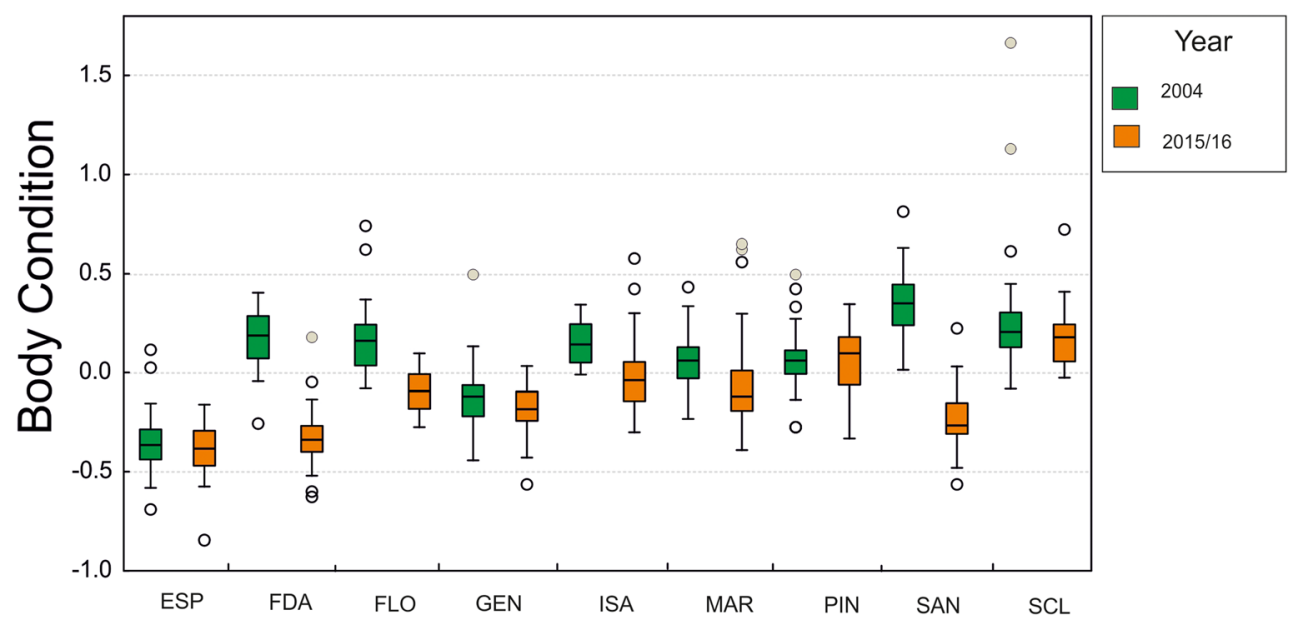

Fig. 2 Boxplot showing body condition index (BCI) of marine iguanas from the same locations in 2004 (i.e., Non-"El Niño" event) and 2015/ 2016 (this study, "El Niño" event). Only marine iguanas from the same locations are considered in this analysis $(N=612)$. Body conditions are

the residuals of a linear regression between (logarithmically transformed) values of weight and total length (See "Material and methods" for details). Median, 25-75\% percentiles, non-outlier range, outliers, and extremes are shown as calculated in Statistica. Population codes as in Table 1

AR, 5.49) and Punta Pitt displayed the lowest values $\left(H_{s}\right.$, $0.65 ; H_{o}, 0.66 ; \mathrm{AR}, 5.01$ ) (Table 3 ). The average values of bacterial species richness calculated for each population were significantly related to host population genetic diversity (Table 4). Populations harboring a more diverse microbiome also displayed higher values of gene diversity $\left(H_{s}\right)$ than populations with less diverse microbiomes (simple linear regression: $\left.F_{1,10}=6.573 ; p=0.028\right)$ as well as allelic richness $\left(F_{1,10}=11.711 ; p=0.007\right)$ (see Table 4 for detailed results, Fig. 4). Moreover, after correcting for phylogenetic signal, these correlations remained significant $(p=0.003$ and $p=$ 0.023 , respectively, for $A R$ and $H_{s}$ ). Bacterial species richness also tended to be related to observed heterozygosity $\left(H_{o}\right)$ $\left(F_{1,10}=3.647 ; p=0.085 ;\right.$ Table 4$)$, but this trend disappeared after phylogenetic correction $(p=0.16)$.

Calculations based on Shannon's effective number of species gave similar results. While allelic richness found across marine iguana populations significantly correlated with diversity and distribution of bacterial OTUs $(p=0.024$; see Fig. S6A in Online Resource 1), the corresponding correlation of gene diversity $\left(H_{s}\right)$ only tended to be significant $(p=0.085$; see Fig. S6B in Online Resource 1).

\section{Discussion}

The morphological and physiological adaptations of Galápagos marine iguanas to the marine environment are unique among lizards worldwide. The specialization of their gut microbiome must also be recognized as a crucial component of this evolutionary adaptation process. This study represents the first work to analyze the possible disturbance of the gut bacterial community of marine iguanas across their distinct island populations during the course of a severe "El Niño" event and connects crucial evolutionary population parameters to gut microbiome diversity. Thus, our study offers important insights that contribute to the appreciation of the gut as an ecosystem which houses a vast number of microbial communities and where the number of species could support the functionality of this ecosystem and potentially aid in its recovery following an external perturbation (Tilman et al. 2014; Oliver et al. 2015). Therefore, unraveling the links between gut microbial diversity and other factors - such as starvation and host genetic diversity - is relevant not only from an evolutionary point of view but could also be important for conservation since it may impact the capacity of threatened species to adapt to changing environmental conditions.

\section{Gut microbiome composition and genetic correlates of variation among populations}

We found that the gut microbiome of the marine iguanas was dominated by Firmicutes, Proteobacteria, and Bacteroidetes, which coincides with what has been found in other vertebrates, such as mammals (Ley et al. 2008; Ochman et al. 2010), amphibians (Bletz et al. 2016; Vences et al. 2016), and reptiles (Kohl et al. 2014; Ren et al. 2016). Bacterial communities belonging to Firmicutes and Bacteroidetes are essential for the degradation of both short-chain carbohydrates and complex polysaccharides of plant origin (Tremaroli and Bäckhed 2012). Firmicutes seem to be abundant in the gut of other lizards, but herbivorous species seem to have larger amounts of these taxa than omnivorous ones (Kohl et al. 2017). A previous study based on fecal samples reported that only a very low relative abundance of Proteobacteria $(\sim 0.6 \%)$ occurred in the gut of marine iguanas (Hong et al. 


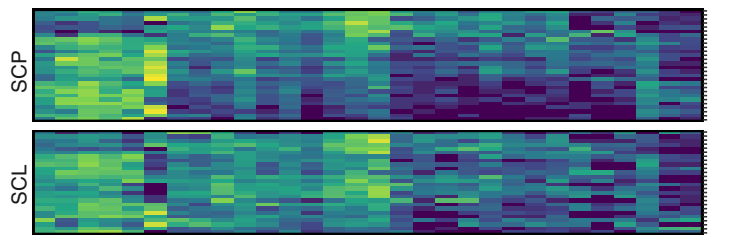

व
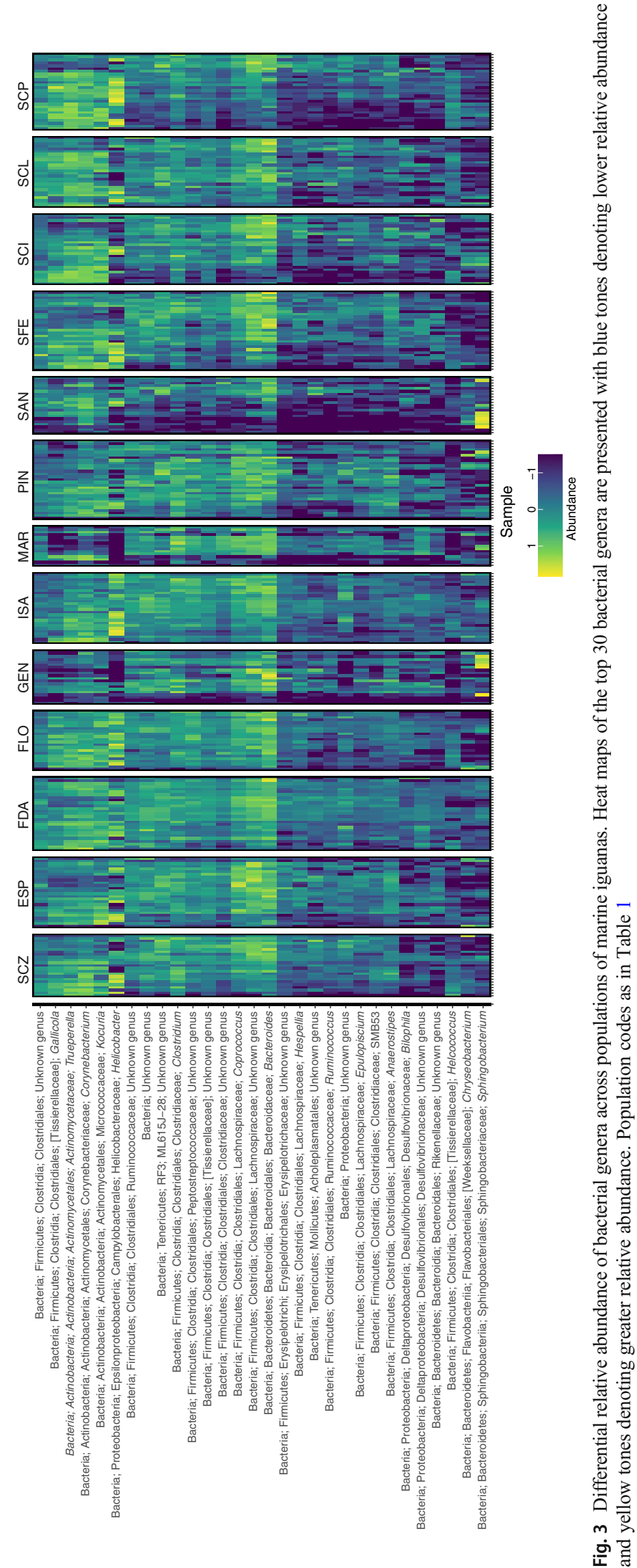
Table 3 Species richness (mean \pm SD of number of OTUs) of gut microbial communities and metrics of population genetic diversity for the island populations of marine iguanas studied

\begin{tabular}{llllll}
\hline Island/site & Subspecies & Species richness & $H_{O}$ & $H_{S}$ & AR \\
\hline Marchena & A. c. hayampi & $165.28 \pm 63.40$ & 0.80 & 0.79 & 7.52 \\
Santa Cruz & A. c. hassi & $146.65 \pm 44.88$ & 0.82 & 0.83 & 8.70 \\
Española & A. c. venustissimus & $143.35 \pm 49.34$ & 0.82 & 0.79 & 8.33 \\
Fernandina & A. c. cristatus & $192.93 \pm 48.14$ & 0.83 & 0.84 & 10.10 \\
Floreana & A. c. venustissimus & $152.09 \pm 42.08$ & 0.78 & 0.81 & 8.88 \\
Genovesa & A. c. nanus & $135.60 \pm 64.92$ & 0.71 & 0.71 & 6.28 \\
Isabela & A. c. cristatus & $184.42 \pm 45.13$ & 0.77 & 0.84 & 10.00 \\
Pinta & A. c. sielmanni & $155.86 \pm 51.86$ & 0.65 & 0.63 & 5.49 \\
Santiago & A. c. wikelskii & $151.10 \pm 66.29$ & 0.78 & 0.78 & 7.72 \\
Santa Fe & A. c. trillmichi & $130.31 \pm 35.28$ & 0.76 & 0.75 & 7.70 \\
San Cristóbal-Punta Pitt & A. c. godzilla & $112.75 \pm 24.68$ & 0.66 & 0.65 & 5.01 \\
San Cristóbal-Isla Lobos & A. c. mertensi & $152.12 \pm 57.28$ & - & - & - \\
San Cristóbal-Loberia & A. c. mertensi & $138.92 \pm 32.11$ & 0.74 & 0.76 & 7.06 \\
San Cristóbal-East Coast & A. c. godzilla & - & 0.77 & 0.74 & 6.18 \\
\hline
\end{tabular}

$H_{o}$ observed heterozygosity, $H_{s}$ gene diversity, $A R$ rarefied allelic richness (for calculation of these parameters, see Material and methods)

Locations with missing data were not included in the final analysis. Marine iguanas from the East coast of San Cristóbal were calculated as part of the underlying microsatellite loci dataset (MacLeod et al. 2015a, b), but have been not analyzed for gut microbiota composition in this study
2011). In contrast, our study suggested that Proteobacteria constitute a large portion of this bacterial community ( $20 \%$ ). Such a drastic disagreement with previous findings cannot be explained only by the different time points of sampling-August to September 2009 in Hong et al. 2011 versus December 2015 to January 2016 in our study — or by different climatic conditions, i.e., sampling outside of the "El Niño" in the previous study versus within the "El Niño" in ours. Other methodological differences between the two studies, notably the different methods used to sample the gut microbial community and the use of different sequencing approaches and primer combinations, might be responsible for this discrepancy (see section Microbial composition and island comparisons in Online Resource 1 for a detailed discussion).
Island populations of $A$. cristatus that display a greater genetic distance to each other were also more distinct in terms of gut microbiome composition. This positive association between host genetic distance and bacterial diversity has also been documented in other animal systems, including laboratory mice strains (Hildebrand et al. 2013) and natural populations of sticklebacks (Smith et al. 2015). Both MRM analysis and partial Mantel tests in our study indicate a relatively strong relationship between beta diversity of the gut microbiome and genetic distance, while geographic distance showed a minor effect. However, we cannot totally rule out a biogeographic effect on gut bacterial communities of marine iguanas because we found a positive relationship between both geographic locations and genetic distances.
Table 4 Species richness of gut microbial communities of marine iguanas (OTU richness) in relation to body condition index (BCI) and genetic variability $\left(H_{\mathrm{O}}\right.$ observed heterozygosity, $H_{\mathrm{S}}$, gene diversity, $A R$ rarefied allelic richness)

\begin{tabular}{|c|c|c|c|c|c|c|c|c|}
\hline \multirow[b]{2}{*}{$\begin{array}{l}\text { Independent } \\
\text { variables }\end{array}$} & \multicolumn{6}{|c|}{ Simple linear models } & \multicolumn{2}{|c|}{$\begin{array}{l}\text { Spearman } \\
\text { correlations }\end{array}$} \\
\hline & $\begin{array}{l}\text { Adjusted } \\
R^{2}\end{array}$ & $F_{\text {(d.f.) }}$ & $\begin{array}{l}\text { Effect size } \\
\text { (partial eta- } \\
\text { squared) }\end{array}$ & $\begin{array}{l}\text { Beta } \\
\text { (B) }\end{array}$ & $\begin{array}{l}T \\
\text { value }\end{array}$ & $P$ & $R$ & $P$ \\
\hline$B C I$ & -0.002 & $0.24_{(1,324)}$ & 0.001 & -0.027 & -0.49 & 0.624 & -0.023 & 0.682 \\
\hline$H_{O}$ & 0.194 & $3.647_{(1,10)}$ & 0.267 & 0.517 & 1.91 & 0.085 & 0.469 & 0.124 \\
\hline$H_{\mathrm{S}}$ & 0.336 & $6.573_{(1,10)}$ & 0.397 & 0.63 & 2.564 & 0.028 & 0.664 & 0.018 \\
\hline$A R$ & 0.493 & $11.711_{(1,10)}$ & 0.539 & 0.734 & 3.422 & 0.007 & 0.608 & 0.036 \\
\hline
\end{tabular}

Significant values $(P<0.05)$ are highlighted in bold. Simple linear models include an intercept, but the values are not shown for simplification. Analyses on the genetic parameters were performed at the population level, while $\mathrm{BCI}$ analyses were performed at the individual level. Each row represents a different linear model and Spearman correlation; therefore each test includes only one predictor: $\mathrm{BCI}, H_{\mathrm{O}}, H_{\mathrm{S}}$, and $\mathrm{AR}$ 

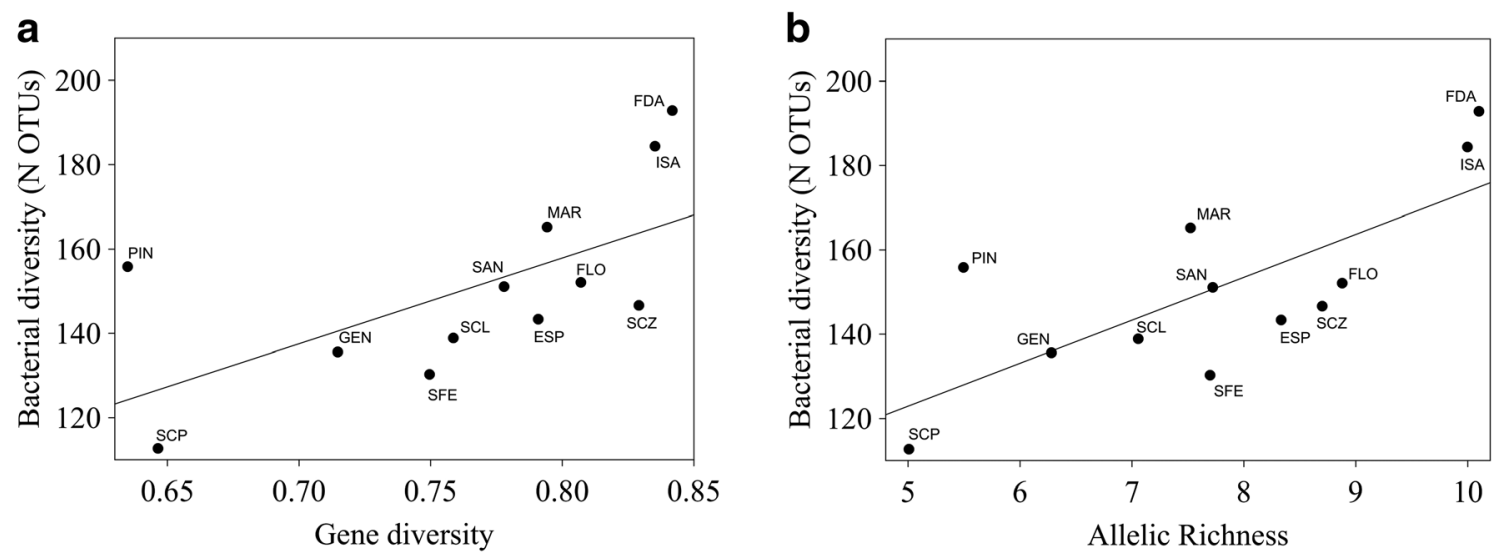

Fig. 4 Correlation of gut bacterial community species richness with host genetic diversity in populations of the marine iguana. (A) Mean number of bacterial operational taxonomic units (OTUs) vs. gene diversity $\left(H_{\mathrm{S}}\right)$ and $(\mathrm{B})$ allelic richness (AR). Population codes are the same as in Fig. 1

\section{Impact of short-term starvation during an intense "EI Niño" event}

Overall, the comparison of body condition of marine iguana populations (sites) during "El Niño" (2015/2016) and non-"El Niño" (2004) years revealed that iguanas displayed lower BCI values in 2015/2016 and thus suffered from starvation on several islands (see Fig. 2 and Table S7 in Online Resource 1). A closer inspection performing a post hoc test revealed that the comparisons of three island sites (Fernandina, Floreana, and Santiago; see Table S8 in Online Resource 1) out of nine comparisons most strongly contribute to the statistical difference (see Table S8 in Online Resource 1). Besides the direct effects of "El Niño" differences in BCI between years might be also caused by stochastic variability due to the extended time span (10 years) between sampling points and the possibility that sampled individuals represent different generations. In this case, individuals might have experienced different environmental conditions during growth causing differences in BCI.

The observed body condition indices of individuals in our study show that distinct populations of marine iguanas were differentially affected by the "El Niño" event of 2015/2016. This might have different causes that are not necessarily mutually exclusive. First, food resources during "El Niño" events may vary considerably among island populations leading to different degrees of starvation. Interestingly, body condition indices also differed between individuals from the same island, as it was the case for La Loberia (highest positive BCI) and Isla Lobos (negative BCI) on San Cristóbal. These locations are only separated by roughly $10 \mathrm{~km}$ coastline and belong to the same subspecies, i.e., A. c. mertensi (Miralles et al. 2017). Therefore, algal food resources - and as a consequence, the degree of starvation - may not only vary among distinct islands but also on a much more local level. Second, differences on marine iguana density among islands may explain the observed variation on body condition across populations. It is known that after an "El Niño" event, marine iguanas can speed up growth rates and populations quickly re-bound likely due to a significant increase in food supply (Wikelski and Trillmich 1997; Wikelski and Nelson 2004). Such a rapid recovery after "El Niño" can be enhanced by a low population density in which foraging competition between survivors is low (Wikelski and Trillmich 1997). Accordingly, differences in population density could also partially explain the variation on BCI observed across the archipelago and would reflect a source of natural variation of this trait.

Periods of fasting and food limitation represent a special physiological situation and can become extremely stressful for individuals when extended during periods of starvation (Romero and Wikelski 2001). As a central component of the digestive system, the gut's microbiome is affected by periods of starvation in many ways. However, these effects vary across vertebrate taxa, and a common pattern has not been found (Kohl et al. 2014). In our study, species richness of the gut bacterial community is not correlated with $\mathrm{BCI}$ in marine iguanas (see Table 4) and seems therefore not to be impacted by severe short-term starvation events such as the one caused by "El Niño". However, our data does not allow us to conclude whether such events have medium- or long-term consequences on the gut microbiome. Furthermore, bacterial groups potentially involved in fermentation and/or degradation of plant material such as Firmicutes and Bacteroidetes appeared to be weakly or not affected by body condition, respectively. This persistence of bacterial communities could be the result of previous and on-going selection for resilient gut microbial strains that have occurred in the course of recurrent ENSO activity in the evolutionary past of marine iguanas.

Another critical factor to consider in our study is the potentially delayed effect of an "El Niño" event on marine iguana populations. For instance, the main period of marine iguana mortality after the 1982/1983 "El Niño" occurred during 1983/1984 (Laurie and Brown 1990). Therefore, our sampling in December 2015 and January 2016 could mark the 
beginning of a more prolonged starvation period and could explain why not all populations displayed drastically reduced $\mathrm{BCI}$ during the beginning of ENSO. Although the long-term effects of the ENSO on marine iguana gut microbiota are unknown, it could be possible that changes in gut bacterial communities are more drastic and visible, after longer periods of starvation associated with ENSO.

\section{Host genetics and microbial diversity}

Based on the variation of twelve non-linked polymorphic microsatellite loci, we identified an unexpected association between host genetic diversity of populations and bacterial diversity of host individuals originating from these populations (see Fig. 4; Fig. S6 in Online Resource 1). Our results indicate that populations characterized by higher genetic diversity levels - based on parameters such as gene diversity and allelic richness-also harbor more diverse gut microbiomes. Given the limitations of our dataset-e.g., lack of data on local algae abundance and specific diet for each island population - it is difficult to provide an explanation for this relationship. A previous study on Gopher tortoises (Gopherus polyphemus) showed a lack of host genetic influence on bacterial gut community structure (Yuan et al. 2015); however, it is questionable whether the limited sampling of distinct host populations may have biased these results.

Here, we propose a novel, testable hypothesis which explains the observed relationship between host genetic and gut bacterial diversity by two cumulative effects related to the size of marine iguana populations. Indeed, census and effective population sizes correlate positively with genetic diversity in marine iguanas (MacLeod and Steinfartz 2016). The first cumulative effect regards the resident part of the marine iguana's gut microbiome, which can be expected to exist in such a specialized herbivore. In principle, all individuals of a specific population would contribute to the gut microbiome of a host population, given that these are social lizards that frequently are in physical contact with each other. Gut microbes might be frequently transmitted between individuals, e.g., when individuals come in touch with other individuals' feces when basking on the rocks or even feeding on such feces (Carpenter 1966). Accordingly, the gut microbiome of each specimen in larger populations would have more opportunities to diversify, and bacterial richness in a random sample of the population - as analyzed in our study - would be higher. Such a mechanism would result in a low dispersion within a population. However, the ordination of fecal bacterial communities indicates that there is substantial variation between individuals of the same population (see Fig. S4) which might depend on the amount of feces sampled from the cloaca. As a second, reinforcing effect, there are indications that populations of marine iguanas differ in foraging habits; for instance, Wikelski and Wrege (2000) report on a single population where a subset of individuals specialized in feeding on land plants. In larger and genetically more diverse populations, it can be expected that a wider array of such genetically determined, adaptive differences may occur, as their increased genetic diversity may relate to more frequent inter-island gene flow favoring the exchange of locally evolved adaptive alleles (MacLeod et al. 2015a). The resulting wider diversity of foraging habits would then lead to recruitment of novel gut microbes into the population and thus to a more diverse microbiome.

To test these hypotheses, future studies should address the origin (resident or transient) of the marine iguana microbiome and the diversity of food plants and foraging mode relative to population sizes in marine iguanas. As a relevant observation for conservation management, we found that populations with a more diversified bacterial community did not perform better during "El Niño"-dependent starvation than populations with lower species richness of their gut bacterial community. This could indicate that digestive performance is dependent on a core microbiome accounting for most of its functionality and calls for future analysis of the marine iguana gut microbiome from an experimental and functional perspective.

Supplementary Information The online version contains supplementary material available at https://doi.org/10.1007/s00114-020-01714-w.

Acknowledgments We are grateful to the Galápagos National Park authority and Ministerio del Ambiente de Ecuador for granting research authorization and permission (PC-08-15 and "Contrato de Acceso a los Recursos Geneticos" No. MAE-DNB-CM-2016-0043). Marcus Krüger, M. Dolores Astudillo, and Rocío Ruiz helped kindly during the fieldwork. We are thankful to the personnel and rangers working in the Galápagos National Park, especially to Maryuri Yépez and Jeffreys Málaga for trip coordination and assistance during fieldwork. We acknowledge the Charles Darwin Research Station (CDRS) and especially Gustavo Jiménez-Uzcátegui for logistic support and help in obtaining all the necessary authorizations and permissions to work in the Galápagos Islands and for exporting the samples. We are indebted to Wacho Tapia and Rocio Ruiz for storing the samples while they were in the Galápagos. We would like to thank Meike Kondermann for performing part of the laboratory work. Amy MacLeod (EditingZoo) improved the language and provided valuable comments on the manuscript. We are grateful for the comments of several reviewers that helped us to strengthen this article at several places.

Funding This work was supported by a grant from the Swiss Friends of the Galápagos Islands and by a postdoctoral research fellowship of the Alexander von Humboldt Foundation to AI.

Data availability Sequence data has been deposited in the Sequence Read Archive (SRA) under BioProject PRJNA658812. Other data are either found in the Supplementary Information (Online Resource 1) or in 
FigShare repository (private link: https://figshare.com/s/ 2cd7c7a2db948eb1ce93; https://doi.org/10.6084/m9.figshare.12936533. $\mathrm{v} 1)$

\section{Compliance with ethical standards}

Conflict of interest The authors declare no conflict of interest.

Ethics approval The Galápagos National Park authority and Ministerio del Ambiente de Ecuador approved this research under the permits PC08-15 and MAE-DNB-CM-2016-0043.

Open Access This article is licensed under a Creative Commons Attribution 4.0 International License, which permits use, sharing, adaptation, distribution and reproduction in any medium or format, as long as you give appropriate credit to the original author(s) and the source, provide a link to the Creative Commons licence, and indicate if changes were made. The images or other third party material in this article are included in the article's Creative Commons licence, unless indicated otherwise in a credit line to the material. If material is not included in the article's Creative Commons licence and your intended use is not permitted by statutory regulation or exceeds the permitted use, you will need to obtain permission directly from the copyright holder. To view a copy of this licence, visit http://creativecommons.org/licenses/by/4.0/.

\section{References}

Adamack AT, Gruber B (2014) PopGenReport: simplifying basic population genetic analyses in R. Methods Ecol Evol 5:384-387. https:// doi.org/10.1111/2041-210X.12158

Amir A, McDonald D, Navas-Molina JA, Kopylova E, Morton JT, Xu ZZ, Kightley EP, Thompson LR, Hyde ER, Gonzalez A, Knight R (2017) Deblur rapidly resolves single-nucleotide community sequence patterns. mSystems 2:e00191-16. https://doi.org/10.1128/ mSystems.00191-16

Ashton KG (2004) Comparing phylogenetic signal in intraspecific and interspecific body size datasets. J Evol Biol 17:1157-1161. https:// doi.org/10.1111/j.1420-9101.2004.00764.x

Barber RT, Chavez FP (1983) Biological consequences of El Nino. Science 222:1203-1210. https://doi.org/10.1126/science.222.4629. 1203

Beasley DE, Koltz AM, Lambert JE, Fierer N, Dunn RR (2015) The evolution of stomach acidity and its relevance to the human microbiome. PLoS One 10:e134116. https://doi.org/10.1371/ journal.pone. 0134116

Benson AK, Kelly SA, Legge R, Ma F, Low SJ, Kim J, Zhang M, Oh PL, Nehrenberg D, Hua KJ, Kachman SD, Moriyama EN, Walter J, Peterson DA, Pomp D (2010) Individuality in gut microbiota composition is a complex polygenic trait shaped by multiple environmental and host genetic factors. Proc Natl Acad Sci U S A 107: 18933-18938. https://doi.org/10.1073/pnas.1007028107

Bletz MC, Goedbloed DJ, Sanchez E, Reinhardt T, Tebbe CC, Bhuju S, Geffers R, Jarek M, Vences M, Steinfartz S (2016) Amphibian gut microbiota shifts differentially in community structure but converges on habitat-specific predicted functions. Nat Commun 7: 13699. https://doi.org/10.1038/ncomms 13699

Bolnick DI, Snowberg LK, Hirsch PE, Lauber CL, Knight R, Caporaso JG, Svanbäck R (2014a) Individuals' diet diversity influences gut microbial diversity in two freshwater fish (threespine stickleback and Eurasian perch). Ecol Lett 17:979-987. https://doi.org/10. 1111/ele. 12301
Bolnick DI, Snowberg LK, Caporaso JG, Lauber C, Knight R, Stutz WE (2014b) Major histocompatibility complex class IIb polymorphism influences gut microbiota composition and diversity. Mol Ecol 23: 4831-4845. https://doi.org/10.1111/mec. 12846

Caporaso JG, Kuczynski J, Stombaugh J, Bittinger K, Bushman FD, Costello EK, Fierer N, Peña AG, Goodrich JK, Gordon JI, Huttley GA, Kelley ST, Knights D, Koenig JE, Ley RE, Lozupone CA, McDonald D, Muegge BD, Pirrung M, Reeder J, Sevinsky JR, Turnbaugh PJ, Walters WA, Widmann J, Yatsunenko T, Zaneveld J, Knight R (2010) QIIME allows analysis of high-throughput community sequencing data. Nat Methods 7:335-336. https://doi.org/ 10.1038/nmeth.f.303

Carpenter CC (1966) The marine iguana of the Galápagos Islands, its behavior and ecology. Proc Calif Acad Sci 32:329-376

Chiari Y, Glaberman S, Tarroso P, Caccone A, Claude J (2016) Ecological and evolutionary influences on body size and shape in the Galápagos marine iguana (Amblyrhynchus cristatus). Oecologia 181:885-894. https://doi.org/10.1007/s00442-016-3618-1

Colston TJ, Noonan BP, Jackson CR (2015) Phylogenetic analysis of bacterial communities in different regions of the gastrointestinal tract of Agkistrodon piscivorus, the cottonmouth snake. PLoS One 10:e0128793. https://doi.org/10.1371/journal.pone.0128793

Cornwell W, Nakagawa S (2017) Phylogenetic comparative methods. Curr Biol 27:R333-R336. https://doi.org/10.1016/j.cub.2017.03. 049

Douglas GM, Maffei VJ, Zaneveld J, Yurgel SN, Brown JR, Taylor CM, Huttenhower C, Langille MGI (2019) PICRUSt2: an improved and extensible approach for metagenome inference. BioRxiv. https:// www.biorxiv.org/content/10.1101/672295v1.full

Felsenstein J (1985) Phylogenies and the comparative method. Am Nat 125:1-15. https://doi.org/10.1086/284325

Frankham R (2005) Genetics and extinction. Biol Conserv 126:131-140

Goslee SC, Urban DL (2007) The ecodist package for dissimilarity-based analysis of ecological data. J Stat Softw 22:1-19. https://doi.org/10. 18637/jss.v022.i07

Greenhalgh K, Meyer KM, Aagaard KM, Wilmes P (2016) The human gut microbiome in health: establishment and resilience of microbiota over a lifetime. Environ Microbiol 18:2103-2116. https://doi.org/ $10.1111 / 1462-2920.13318$

Hervé M. (2017) RVAideMemoire: testing and plotting procedures for biostatistics. https://cran.r-project.org/web/packages/ RVAideMemoire/ind

Hildebrand F, Nguyen TLA, Brinkman B, Yunta RG, Cauwe B, Vandenabeele P, Liston A, Rases J (2013) Inflammationassociated enterotypes, host genotype, cage and inter-individual effects drive gut microbiota variation in common laboratory mice. Genome Biol 14:R4. https://doi.org/10.1186/gb-2013-14-1-r4

Hong PY, Wheeler E, Cann IK, Mackie RI (2011) Phylogenetic analysis of the fecal microbial community in herbivorous land and marine iguanas of the Galápagos Islands using 16S rRNA-based pyrosequencing. ISME J 5:1461-1470. https://doi.org/10.1038/ismej. 2011.33

Jombart T (2008) Adegenet: a R package for the multivariate analysis of genetic markers. Bioinformatics 24:1403-1405. https://doi.org/10. 1093/bioinformatics/btn129

Jost L (2006) Entropy and diversity. Oikos 113:363-375. https://doi.org/ 10.1111/j.2006.0030-1299.14714.x

Kamada N, Chen GY, Inohara N, Núñez G (2013) Control of pathogens and pathobionts by the gut microbiota. Nat Immunol 14:685-690. https://doi.org/10.1038/ni.2608

Kohl KD, Amaya J, Passement CA, Dearing MD, McCue MD (2014) Unique and shared responses of the gut microbiota to prolonged fasting: a comparative study across five classes of vertebrate hosts. FEMS Microbiol Ecol 90:883-894. https://doi.org/10.1111/15746941.12442 
Kohl KD, Brun A, Magallanes M, Brinkerhoff J, Laspiur A, Acosta JC, Caviedes-Vidal E, Bordenstein SR (2017) Gut microbial ecology of lizards: insights into diversity in the wild, effects of captivity, variation across gut regions and transmission. Mol Ecol 26(4):11751189. https://doi.org/10.1111/mec.13921

Kozich JJ, Westcott SL, Baxter NT, Highlander SK, Schloss PD (2013) Development of a dual-index sequencing strategy and curation pipeline for analyzing amplicon sequence data on the MiSeq Illumina sequencing platform. Appl Environ Microbiol 79:5112-5120. https://doi.org/10.1128/AEM.01043-13

Kwon S, Park S, Lee B, Yoon S (2013) In-depth analysis of interrelation between quality scores and real errors in Illumina reads. Conf Proc IEEE Eng Med Biol Soc 2013:635-638

Langille MGI, Jesse Z, Gregory JC, Daniel MD, Dan K, Reyes JA, Clemente JC, Burkepile DE, Vega Thurber RL, Knight R, Beiko RG, Huttenhower C (2013) Predictive functional profiling of microbial communities using 16S rRNA marker gene sequences. Nat Biotechnol 31:814-821. https://doi.org/10.1038/nbt.2676

Lankau EW, Hong PY, Mackie RI (2012) Ecological drift and local exposures drive enteric bacterial community differences within species of Galápagos iguanas. Mol Ecol 21:1779-1788. https://doi.org/ 10.1111/j.1365-294X.2012.05502.x

Laurie WA (1990) Effects of the 1982-1983 El Niño-Southern Oscillation event on marine iguana (Amblyrhynchus cristatus, Bell, 1825) populations on Galápagos. In: ed. Glynn PW (ed) Global ecological consequences of the 1982-1983 El NiñoSouthern Oscillation, Elsevier Oceanography Series, New York, pp. 361-380. https://doi.org/10.1016/S0422-9894(08)70041-2

Laurie WA, Brown D (1990) Population biology of marine iguanas (Amblyrhynchus cristatus). II. Changes in annual survival rates and the effects of size, sex, age and fecundity in a population crash. J Animal Ecol 59:529-544. https://doi.org/10.2307/4879

Ley RE, Turnbaugh PJ, Klein S, Gordon JI (2006) Microbial ecology: human gut microbes associated with obesity. Nature 444:10221023. https://doi.org/10.1038/4441022a

Ley RE, Hamady M, Lozupone C, Turnbaugh PJ, Ramey RR, Bircher JS, Schlegel ML, Tucker TA, Schrenzel MD, Knight R, Gordon JI (2008) Evolution of mammals and their gut microbes. Science 320:1647-1651. https://doi.org/10.1126/science.1155725

Mackie RI, Rycyk M, Ruemmler RL, Aminov RI, Wikelski M (2004) Biochemical and microbiological evidence for fermentative digestion in free-living land iguanas (Conolophus pallidus) and marine iguanas (Amblyrhynchus cristatus) on the Galápagos archipelago. Physiol Biochem Zool 77:127-138. https://doi.org/10.1086/383498

MacLeod A, Steinfartz S (2016) The conservation status of the Galápagos marine iguanas, Amblyrhynchus cristatus: a molecular perspective. Amphib-Reptil 37:91-109. https://doi.org/10.1163/1568538100003035

MacLeod A, Rodríguez A, Vences M, Orozco-terWengel P, García C, Trillmich F, Gentile G, Caccone A, Quezada G, Steinfartz S (2015a) Hybridization masks speciation in the evolutionary history of the Galápagos marine iguana. Proc R Soc B 282:20150425. https:// doi.org/10.1098/rspb.2015.0425

MacLeod A, Rodríguez A, Vences M, Orozco-terWengel P, García C, Trillmich F, Gentile G, Caccone A, Quezada G, Steinfartz S (2015b) Data from: hybridization masks speciation in the evolutionary history of the Galápagos marine iguana. Dryad Digital Repository. https://doi.org/10.5061/dryad.pp6bm

Martin MO, Gilman FR, Weiss SL (2010) Sex-specific asymmetry within the cloacal microbiota of the striped plateau lizard, Sceloporus virgatus. Symbiosis 51:97-105. https://doi.org/10.1007/s13199010-0078-y

Maslowski KM, Vieira AT, Ng A, Kranich J, Sierro F, Yu D, Schilter HC, Rolph MS, Mackay F, Artis D, Xavier RJ, Teixeira MM, Mackay CR (2009) Regulation of inflammatory responses by gut microbiota and chemoattractant receptor GPR43. Nature 461:12821286. https://doi.org/10.1038/nature08530

Miralles A, Macleod A, Rodríguez A, Ibáñez A, Jiménez-Uzcategui G, Quezada G, Vences M, Steinfartz S (2017) Shedding light on the imps of darkness: an integrative taxonomic revision of the Galápagos marine iguanas (genus Amblyrhynchus). Zool J Linnean Soc 181:678-710. https://doi.org/10.1093/zoolinnean/ zlx007

Nelson TM, Rogers TL, Carlini AR, Brown MV (2013) Diet and phylogeny shape the gut microbiota of Antarctic seals: a comparison of wild and captive animals. Environ Microbiol 15:1132-1145. https:// doi.org/10.1111/1462-2920.12022

Ochman H, Worobey M, Kuo CH, Ndjango JBN, Peeters M, Hahn BH, Hugenholtz P (2010) Evolutionary relationships of wild hominids recapitulated by gut microbial communities. PLoS Biol 8:e1000546. https://doi.org/10.1371/journal.pbio.1000546

Oksanen J, Blanchet FG, Friendly M, Kindt R, Legendre P, McGlinn D, Minchin PR, O'Hara RB, Simpson GL, Solymos P, Stevens MHM, Szoecs E, Wagner H (2019) Vegan: community ecology package. R package version 2:5-4 http://CRAN.R-project.org/package=vegan

Oliver TH, Heard MS, Isaac NJ et al (2015) Biodiversity and resilience of ecosystem functions. Trends Ecol Evol 30:673-684. https://doi.org/ 10.1016/j.tree.2015.08.009

Ostaff MJ, Stange EF, Wehkamp J (2013) Antimicrobial peptides and gut microbiota in homeostasis and pathology. EMBO Mol Med 5:14651483. https://doi.org/10.1002/emmm.201201773

Paradis E, Claude J, Strimmer K (2004) APE: analyses of phylogenetics and evolution in R language. Bioinformatics 20:289-290. https:// doi.org/10.1093/bioinformatics/btg412

Parfrey LW, Walters WA, Lauber CL, Clemente JC, Berg-Lyons D, Teiling C, Kodira C, Mohiuddin M, Brunelle J, Driscoll M, Fierer N, Gilbert JA, Knight R (2014) Communities of microbial eukaryotes in the mammalian gut within the context of environmental eukaryotic diversity. Front Microbiol 5:298. https://doi.org/10. 3389/fmicb.2014.00298

Peakall R, Smouse PE (2006) GENALEX 6: genetic analysis in Excel. Population genetic software for teaching and research. Mol Ecol Notes 6:288-295. https://doi.org/10.1111/j.1471-8286.2005. 01155.x

Peakall R, Smouse PE (2012) GenAlEx 6.5: genetic analysis in Excel. Population genetic software for teaching and research - an update. Bioinformatics 28:2537-2539. https://doi.org/10.1093/ bioinformatics/bts 460

Pop M (2012) We are what we eat: how the diet of infants affects their gut microbiome. Genome Biol 13:152. https://doi.org/10.1186/gb2012-13-4-152

Price MN, Dehal PS, Arkin AP (2010) FastTree 2-approximately maximum-likelihood trees for large alignments. PLoS One 5: e9490. https://doi.org/10.1371/journal.pone.0009490

Price JT, Paladino FV, Lamont MM, Witherington BE, Bates ST, Sole T (2017) Characterization of the juvenile green turtle (Chelonia mydas) microbiome throughout an ontogenetic shift from pelagic to neritic habitats. PLoS One 12:e0177642. https://doi.org/10. 1371/journal.pone. 0177642

R Core Team (2013) R: a language and environment for statistical computing, Vienna, Austria

Ren T, Kahrl AF, Wu M, Cox RM (2016) Does adaptive radiation of a host lineage promote ecological diversity of its bacterial communities? A test using gut microbiota of Anolis lizards. Mol Ecol 25: 4793-4804. https://doi.org/10.1111/mec.13796

Romero LM, Wikelski M (2001) Corticosterone levels predict survival probabilities of Galápagos marine iguanas during El Niño events. Proc Natl Acad Sci U S A 98:7366-7370. https://doi.org/10.1073/ pnas. 131091498

Rubino F, Carberry C, Waters SM, Kenny D, McCabe MS, Creevey CJ (2017) Divergent functional isoforms drive niche specialisation for 
nutrient acquisition and use in rumen microbiome. ISME J 11:932944. https://doi.org/10.1038/ismej.2016.172

Sabino-Pinto J, Bletz MC, Islam MM, Shimizu N, Bhuju S, Geffers R, Jarek M, Kurabayashi A, Vences M (2016) Composition of the cutaneous bacterial community in Japanese amphibians: effects of captivity, host species, and body region. Microb Ecol 72:460-469. https://doi.org/10.1007/s00248-016-0797-6

Shepherd SA, Hawkes MW (2005) Algal food preferences and seasonal foraging strategy of the marine iguana, Amblyrhynchus cristatus, on Santa Cruz, Galápagos. Bull Mar Sci 77:51-72

Smith CC, Snowberg LK, Caporaso JG, Knight R, Bolnick DI (2015) Dietary input of microbes and host genetic variation shape amongpopulation differences in stickleback gut microbiota. ISME J 9: 2515-2526. https://doi.org/10.1038/ismej.2015.64

Sommer F, Bäckhed F (2013) The gut microbiota - masters of host development and physiology. Nat Rev Microbiol 11:227-238. https:// doi.org/10.1038/nrmicro2974

Spor A, Koren O, Ley R (2011) Unravelling the effects of the environment and host genotype on the gut microbiome. Nat Rev Microbiol 9:279-290. https://doi.org/10.1038/nrmicro2540

Steinfartz S, Glaberman S, Lanterbecq D, Marquez C, Rassmann K, Caccone A (2007) Genetic impact of a severe El Niño event on Galápagos marine iguanas (Amblyrhynchus cristatus). PLoS One 2:e1285. https://doi.org/10.1371/journal.pone.0001285

Steinfartz S, Glaberman S, Lanterbecq D, Russello MA, Rosa S, Hanley TC, Marquez C, Snell HL, Snell HM, Gentile G, Dell'Olmo G, Powell AM, Caccone A (2009) Progressive colonization and restricted gene flow shape island-dependent population structure in Galápagos marine iguanas (Amblyrhynchus cristatus) BMC Evol Biol 9:297. https://doi.org/10.1186/1471-2148-9-297

Stone GN, Neel S, Felsenstein J (2011) Controlling for non-independence in comparative analysis of patterns across populations within species. Phil Trans R Soc B 366:1410-1424. https://doi.org/10.1098/ rstb.2010.0311

Tilman D, Isbell F, Cowles JM (2014) Biodiversity and ecosystem functioning. Annu Rev Ecol Evol Syst 45:471-493. https://doi.org/10. 1146/annurev-ecolsys-120213-091917

Tremaroli V, Bäckhed F (2012) Functional interactions between the gut microbiota and host metabolism. Nature 489:242-249. https://doi. org/10.1038/nature11552

Turnbaugh PJ, Bäckhed F, Fulton L, Gordon JI (2008) Diet-induced obesity is linked to marked but reversible alterations in the mouse distal gut microbiome. Cell Host Microbe 3:213-223. https://doi. org/10.1016/j.chom.2008.02.015
United States Climate Prediction Center (2019) Historical El Niño/La Niña episodes (1950-present). https://origin.cpc.ncep.noaa.gov/ products/analysis_monitoring/ensostuff/ONI_v5.php (1 February 2019)

Vavrek MJ (2011) Fossil: palaeoecological and palaeogeographical analysis tools. Palae Electronica 14:1T

Vences M, Lyra ML, Kueneman JG, Bletz MC, Archer HM, Canitz J, Handreck S, Randrianiaina RD, Struck U, Bhuju S, Jarek M, Geffers R, McKenzie VJ, Tebbe CC, Haddad CFB, Glos J (2016) Gut bacterial communities across tadpole ecomorphs in two diverse tropical anuran faunas. Sci Nat 103:25. https://doi.org/10.1007/s00114-016$1348-1$

Vitousek M, Rubenstein D, Wikelski M, Reilly S, McBrayer L, Miles D (2007) The evolution of foraging behavior in the Galapagos marine iguana: natural and sexual selection on body size drives ecological, morphological, and behavioral specialization. In: Reilly SM, McBrayer LB, Miles DB (eds) Lizard ecology: the evolutionary consequences of foraging mode. University Press Cambridge, Cambridge, pp 491-507. https://doi.org/10.1017/ CBO9780511752438.018

Wang Q, Garrity GM, Tiedje JM, Cole JR (2007) Naive Bayesian classifier for rapid assignment of rRNA sequences into the new bacterial taxonomy. Appl Environ Microbiol 73:5261-5267. https://doi.org/ 10.1128/AEM.00062-07

Wikelski M, Nelson K (2004) Conservation of Galápagos marine iguanas (Amblyrhynchus cristatus). Iguana 11:191-197

Wikelski M, Trillmich F (1997) Body size and sexual size dimorphism in marine iguanas fluctuate as a result of opposing natural and sexual selection: an island comparison. Evolution 51:922-936. https://doi. org/10.1111/j.1558-5646.1997.tb03673.x

Wikelski M, Wrege PH (2000) Niche expansion, body size, and survival in Galápagos marine iguanas. Oecologia 124:107-115. https://doi. org/10.1007/s004420050030

Wikelski M, Gall B, Trillmich F (1993) Ontogenetic changes in food intake and digestion rate of the herbivorous marine iguana (Amblyrhynchus cristatus, Bell). Oecologia 94:373-379. https:// doi.org/10.1007/BF00317112

Yuan ML, Dean SH, Longo AV, Rothermel BB, Tuberville TD, Zamudio KR (2015) Kinship, inbreeding and fine-scale spatial structure influence gut microbiota in a hindgut-fermenting tortoise. Mol Ecol 24:2521-2536. https://doi.org/10.1111/mec.13169

Publisher's note Springer Nature remains neutral with regard to jurisdictional claims in published maps and institutional affiliations. 